\title{
HEPATIC STEATOSIS: AN AETIOHISTOPATHOLOGICAL STUDY
}

\author{
Gauri Shrikrishna Metkar ${ }^{1}$
}

${ }_{1}^{1}$ Assistant Professor, Department of Pathology, A. J. Institute of Medical Sciences and Research Centre.

\section{ABSTRACT}

\section{BACKGROUND}

Fatty liver disease, i.e. hepatic steatosis defined as hepatic lipid accumulation greater than $5-10 \%$ of liver weight.1-3 has become a common health problem in both developed and developing countries. Morphologically fatty liver is of two types: microvesicular and macrovesicular. Macrovesicular steatosis is a chronic condition associated with various risk factors like alcoholism, diabetes mellitus, obesity, etc. The aim of present study was to analyse various aetiological factors associated with macrovesicular hepatic steatosis and find its correlation with the grade of steatosis.

\section{METHODOLOGY}

This retrospective and prospective study was conducted in histopathology laboratory of a tertiary health care centre in Mangalore, Karnataka, from 2009 to 2014; 120 cases of liver biopsies and autopsy liver tissue of adults ( $\geq 18$ years) showing histologically confirmed macrovesicular steatosis in $>10 \%$ hepatocytes were analysed for aetiology and grade of steatosis.

\section{RESULT}

Hepatic steatosis was observed mainly in middle aged (31-50 years) males. ALD and non-alcoholic steatohepatitis (NASH) were most common causes followed by infections like TB, HCV, HBV, HIV and other causes like CPC (Chronic Passive Congestion) liver and drugs. Spearmen's correlation coefficient was used to analyse correlation between aetiology and grade of steatosis. ALD and NASH were most common causes for severe steatosis. ALD and NASH were also common causes for mild-to-moderate grade of steatosis. Mainly moderate-to-severe steatosis was found in association with TB, HCV, HBV, HIV. CPC cases predominantly showed moderate steatosis. The correlation between aetiology and grade of steatosis was found to be statistically significant. Drug induced steatosis was mostly severe grade, but the number of cases were too less to consider it statistically significant.

\section{CONCLUSION}

Various causes like ALD, NASH, TB, HCV, HBV and HIV infections, CPC and rarely drugs should be considered in cases of macrovesicular hepatic steatosis and histopathological sections of liver tissue should be studied extensively to rule out higher grades of steatosis.

\section{KEYWORDS}

Fatty Liver, Alcoholic Liver Disease, NASH.

HOW TO CITE THIS ARTICLE: Metkar GS. Hepatic steatosis: an aetiohistopathological study. J. Evolution Med. Dent. Sci. 2016; 5 (53):3502-3505, DOI: $10.14260 /$ jemds/2016/808

\section{INTRODUCTION}

Fatty liver, i.e. hepatic steatosis is the most common finding in liver biopsies. Fatty liver disease is defined as hepatic fat accumulation more than $5-10 \%$ of liver weight.1-3 This condition which is common in both developed as well as developing countries like India is associated with various aetiological factors, which differ according to the type of steatosis. Hepatic steatosis is mainly divided into two types microvesicular and macrovesicular. In micro-vesicular steatosis, numerous small lipid vesicles accumulate in hepatocytes, which leave the nucleus at centre. It is seen in conditions like acute fatty liver of pregnancy and Reye's syndrome. ${ }^{4}$ It is associated with severe and acute form of liver injury. In contrast macrovesicular steatosis is a chronic condition, wherein large single lipid droplet accumulates in the hepatocyte pushing nucleus to the periphery.

Financial or Other, Competing Interest: None.

Submission 25-05-2016, Peer Review 19-06-2016,

Acceptance 24-06-2016, Published 02-07-2016.

Corresponding Author:

Dr. Gauri Shrikrishna Metkar

Flat 005, Landlinks Paradise 1 Apartment,

Derebail Konchady,

Mangalore-575008,

Karnataka State.

E-mail: drgauribhat@gmail.com

DOI: $10.14260 /$ jemds/2016/808
Causative factors for macrovesicular steatosis are broadly divided into Alcoholic Liver Disease (ALD) and Non-Alcoholic Fatty Liver Disease (NAFLD). In the present study, we have analysed the frequency of different aetiological factors in macrovesicular steatosis in adult population and its correlation with the grade of steatosis.

\section{METHODOLOGY}

This is a retrospective as well as prospective histopathological study done in histopathology laboratory of AJ Institute of Medical Sciences and Research Centre, Mangalore, Karnataka, from 2009 to 2014 (5 years).

\section{Inclusion Criteria}

Total 120 cases of liver biopsy and autopsy liver tissue of adults $\geq 18$ years of age showing macrovesicular steatosis in more than $10 \%$ hepatocytes were included in the study.

\section{Exclusion Criteria}

Cases in which histopathology sections were showing mainly microvesicular steatosis and those cases where aetiology of steatosis could not be confirmed were excluded from the study.

All 120 cases were studied for aetiology and grading of macrovesicular steatosis and their correlation with each 
other. Grading of steatosis was done using guidelines of Brunt et $\mathrm{al}^{5}$ (With modification) and Mofrad et al. ${ }^{6} \mathrm{H}$ and $\mathrm{E}$ stained sections of liver tissue were observed under scanner view (40x) and grading of macrovesicular steatosis was done as follows:

- Grade 1 (Mild): Seen in $\geq 10 \%$, but $\leq 30 \%$ hepatocytes.

- Grade 2 (Moderate): Seen in $>30 \%$, but $\leq 60 \%$ hepatocytes.

- $\quad$ Grade 3 (Severe): Seen in $>60 \%$ hepatocytes.

\section{STATISTICS}

Data was analysed using Spearman's correlation coefficient to evaluate the correlation between aetiology and grade of hepatic steatosis; $<0.05$ was set as the level of significance.

\section{RESULT}

We found that out of total 120 cases, 84 (70\%) were males and $36(30 \%)$ were females. Main clustering of cases was seen in the age group of 31-50 years (78 cases, i.e. 65\%). Thus, abnormal findings were more commonly seen in middle aged males.

\begin{tabular}{|c|c|c|c|}
\hline $\begin{array}{c}\text { Age Group } \\
\text { (Years) }\end{array}$ & $\begin{array}{c}\text { Males } \\
(\mathbf{\%})\end{array}$ & $\begin{array}{c}\text { Females } \\
(\mathbf{\% )}\end{array}$ & $\begin{array}{c}\text { Total } \\
(\mathbf{\% )}\end{array}$ \\
\hline $18-20$ & 2 & 1 & 3 \\
\hline $21-30$ & 11 & 3 & 14 \\
\hline $31-40$ & 25 & 16 & 41 \\
\hline $41-50$ & 27 & 10 & 37 \\
\hline $51-60$ & 16 & 2 & 18 \\
\hline $61-70$ & 2 & 3 & 5 \\
\hline $71-80$ & 1 & 1 & 2 \\
\hline Total & $\mathbf{8 4}(\mathbf{7 0} \%)$ & $\mathbf{3 6}(\mathbf{3 0} \%)$ & $\mathbf{1 2 0}$ \\
\hline \multicolumn{4}{|r}{ Table 1: Demographic Profile of Patients $(\mathbf{N = 1 2 0})$} \\
\hline
\end{tabular}

As shown in Table 2, Alcoholic liver disease was the most common aetiological factor (30.8\% cases) in our study. NASH was the second most common cause accounting for $23.3 \%$ cases. Amongst infectious causes, TB was most common.

\begin{tabular}{|c|c|c|c|}
\hline $\begin{array}{c}\text { Sr. } \\
\text { No. }\end{array}$ & $\begin{array}{c}\text { Aetiology of Hepatic } \\
\text { Steatosis }\end{array}$ & $\begin{array}{c}\text { Number of } \\
\text { Cases }\end{array}$ & Percentage \\
\hline 1. & $\begin{array}{c}\text { Alcoholic liver } \\
\text { disease }\end{array}$ & 37 & 30.8 \\
\hline 2. & $\begin{array}{c}\text { Non-alcoholic steato- } \\
\text { hepatitis }\end{array}$ & 28 & 23.3 \\
\hline 3. & TB & 15 & 12.5 \\
\hline 4. & HCV & 12 & 10 \\
\hline 5. & HBV & 11 & 9.1 \\
\hline 6. & HIV & 10 & 8.3 \\
\hline 7. & CPC & 5 & 4.1 \\
\hline 8. & Drugs & 2 & 1.6 \\
\hline \multicolumn{3}{|c|}{ Table 2: Aetiology of Hepatic Steatosis } \\
\hline \multicolumn{2}{|c|}{} \\
\hline
\end{tabular}

\begin{tabular}{|c|c|c|c|c|c|}
\hline \multirow[b]{2}{*}{$\begin{array}{l}\text { Sr. } \\
\text { No. }\end{array}$} & \multirow{2}{*}{$\begin{array}{c}\text { Cause of } \\
\text { Hepatic } \\
\text { Steatosis }\end{array}$} & \multicolumn{3}{|c|}{ Grade of Steatosis } & \multirow[b]{2}{*}{ Total } \\
\hline & & $\begin{array}{c}\text { Mild } \\
\text { (Grade1) }\end{array}$ & $\begin{array}{l}\text { Moderate } \\
\text { (Grade 2) }\end{array}$ & $\begin{array}{c}\text { Severe } \\
\text { (Grade 3) }\end{array}$ & \\
\hline 1. & ALD & 9 & 9 & $\begin{array}{c}19 \\
(51.3 \%)\end{array}$ & 37 \\
\hline 2. & NASH & 6 & $14(50 \%)$ & 8 & 28 \\
\hline 3. & TB & 2 & 4 & 9 & 15 \\
\hline 4. & $\mathrm{HCV}$ & 2 & 7 & 3 & 12 \\
\hline 5. & HBV & 6 & 4 & 1 & 11 \\
\hline 6. & HIV & 2 & 5 & 3 & 10 \\
\hline 7. & $\mathrm{CPC}$ & 1 & 3 & 1 & 5 \\
\hline \multirow[t]{2}{*}{8.} & Drugs & 0 & 1 & 1 & 2 \\
\hline & Total & 28 & 47 (39.1\%) & $4537.5 \%)$ & 120 \\
\hline \multicolumn{6}{|c|}{ Table 3: Grade of Hepatic Steatosis in Various Aetiologies } \\
\hline
\end{tabular}

As shown in Table 3, moderate grade (Grade 2) of steatosis was most commonly seen (39.1\% cases) followed by severe grade (37.5\% cases). Most common cause of moderate steatosis was NASH, whereas ALD was most common cause of severe steatosis. Most common grade of steatosis seen in ALD was grade 3 , i.e. severe steatosis (51.3\%), whereas amongst NASH cases moderate grade of steatosis was most common (50\%). Most common grade of steatosis in TB was grade 3. Amongst hepatotropic virus infections, HCV showed moderate grade of steatosis most commonly, whereas in HBV infected cases mild steatosis was most common. CPC cases showed moderate steatosis mostly. Drug induced steatosis cases showed moderate and severe grade of steatosis with equal frequency. Spearmen's correlation coefficient was utilized to analyse correlation between various aetiological factors and grade of steatosis considering $<0.05$ as level of significance. It was found that the correlation between above mentioned aetiological factors and grade of steatosis was statistically significant in all aetiologies except drug-induced steatosis. The number of cases of drug-induced steatosis were too less to consider statistically significant.

\section{DISCUSSION}

The demographic profile of our study showed clustering of cases in middle aged males (31 to 50 years). Richard Guerrero et $\mathrm{al}^{7}$ and Hideyuki Kojima et al ${ }^{8}$ found similar results. Amongst Indian population, Singh DK et $\mathrm{al}^{9}$ found male:female ratio of 3.1:1 among 71 NASH cases.

The most common risk factor for hepatic steatosis in our cases was alcoholic liver disease and non-alcoholic steatohepatitis. Various past and recent studies done on western as well as Indian population have well established that the chronic alcoholism and NASH are the two most common causes of fatty liver disease.8,10-12,13 Leevy CM.14 analysed risk factors for fatty liver in 270 patients and found alcoholism to be the most common cause $43.3 \%$ followed by diabetes $6.3 \%$. NASH is increasingly becoming causative factor for fatty liver disease because of increased incidence of obesity and diabetes mellitus. Association between TB and fatty liver is well established. $15 \mathrm{~TB}$ can cause fatty liver due to malnutrition, anoxia, starvation and tuberculous toxicity itself. Frequency of fatty change in pulmonary and extrapulmonary TB in various studies ranges from 20-44\%.16-19 In our study, HCV and HBV were responsible for hepatic steatosis in $812(10 \%)$ and $11(9.1 \%)$ cases each. Macrovesicular hepatic steatosis is a common histological finding in patients with hepatitis $\mathrm{C}$ infection and known to be associated with progression of fibrosis independently in the absence of risk factors like alcohol and obesity. ${ }^{20,21}$ The worldwide frequency of steatosis in HCV is $31-72 \%{ }^{20-25,26}$ Hepatic steatosis is not commonly seen in hepatitis B infection; however, $10-20 \%$ patients of hepatitis B can have steatosis possibly due to overlap with metabolic syndrome as shown by Rozario et $\mathrm{al}^{27} ; 31-72 \%$ frequency of $\mathrm{HBV}$ associated steatosis is seen in various studies. ${ }^{20-23}$ HIV was responsible for 10 (8.3\%) of our cases. Steatosis in HIV can be because of malnutrition or therapy related. ${ }^{28}$ It can be associated with HCV-HBV co-infection. CPC (In right-sided heart failure) was responsible for 5 cases (4.1\%) in our study. Sung KC et al29 have shown association between cardiovascular disease and fatty liver disease. Drug-induced steatosis was found in only 2 cases. 
Drugs responsible were methotrexate and warfarin in 1 case each. These drugs are known to cause hepatic steatosis. ${ }^{30}$ Elizabeth $\mathrm{B}$ et al ${ }^{5}$ found grades of steatosis in ALD and HCV cases comparable to our study. Naga Chalasani et al 31 found mild, moderate and severe steatosis in 44\%, 31\% and $25 \%$ of biopsies, respectively. Thus mild steatosis was most common among their patients. However, moderate steatosis was also seen in significant number of cases $31 \%$. Gordon et $\mathrm{al}^{32}$ found grades of steatosis in HCV and HBV cases similar to our findings. Grades of hepatic steatosis seen in other aetiologies, i.e. TB, HIV, CPC drugs were comparable with other studies. ${ }^{14,33,34}$

\section{CONCLUSION}

Aetiologies like ALD, NASH, TB, HCV, HBV, HIV, CPC and drugs should be evaluated while analysing macrovesicular hepatic steatosis. Also the histopathological sections should be studied extensively to find out the grade and severity of steatosis.

\section{REFERENCES}

1. Reddy JK, Rao MS. Lipid metabolism and liver inflammation II fatty liver disease and fatty acid oxidation. Am J Physiol Gastrointest Liver Physiol 2006;290(5):G852-8.

2. Adams LA, Lymp JF, St Sauver J, et al. The natural history of non-alcoholic fatty liver disease: a population-based cohort study. Gastroenterology 2005;129(1):113-21.

3. Crabb DW, Galli A, Fischer $M$, et al. Molecular mechanisms of alcoholic fatty liver: role of peroxisome proliferator activated receptor alpha. Alcohol 2004;34(1):35-8.

4. Goldman, Lee. Cecil textbook of medicine. Set, Text with continually updated online reference. Philadelphia: WB Saunders company 2003;2.

5. Brunt EM, Ramrakhiani S, Cordes BG, et al. Concurrence of histologic features of steatohepatitis with other forms of chronic liver disease. Mod Pathol 2003;16(1):49-56.

6. Mofrad P, Contos MJ, Haque M, et al. Clinical and histologic spectrum of non-alcoholic fatty liver disease associated with normal ALT values. Hepatology 2003;37(6):1286-92.

7. Guerrero R, Vega GL, Grundy SM, et al. Ethnic differences in hepatic steatosis: an insulin resistance paradox? Hepatology 2009;49(3):791-801.

8. Kojima H, Sakurai S, Uemura M, et al. Difference and similarity between non-alcoholic steatohepatitis and alcoholic liver disease. Alcoholism: clinical and experimental research 2005;29(Suppl S3):259s-63s.

9. Singh DK, Sakhuja P, Malhotra V, et al. Independent predictors of steatohepatitis and fibrosis in Asian Indian patients with non-alcoholic steatohepatitis. Dig Dis Sci 2008;53(7):1967-76.

10. Bellentani S, Saccoccio G, Masutti F, et al. Prevalence of and risk factors for hepatic steatosis in northern Italy. Ann Intern Med 2000;132(2):112-7.

11. James OF, Day CP. NASH: a disease of emerging identity and importance. J Hepatol 1998;29(3):495-501.

12. Sheth SG, Gordon FD, Chopra S. Non-alcoholic steatohepatitis. Annals of internal medicine 1997;126(2):137-45.
13. Dhawan PS, Chopra KB, Bhandarkar PB, et al. A profile of alcoholic dis. Ind J Gastroenterol 1993;12 (Suppl 2): A91-4.

14. Leevy CM. A study of 270 patients with biopsy proven fatty liver and a review of the literature. Medicine (Baltimore) 1962;41:249-76.

15. Ban B. Hepatic damage in chronic pulmonary tuberculosis. Am Rev Tuberc 1955;72(1):71-90.

16. Korn RJ, Kellow WF, Heller P, et al. Hepatic involvement in extrapulmonary TB; histologic and functional characteristics. Am J Med 1959;27(1):60-71.

17. Mukherji B, Gulati PD, Vyas PB. Hepatic involvement in TB: a clinicopathological study. J Assoc Physicians India 1968;16:451-6.

18. Gambhir MS, Goyal SK, Rawat ML. Hepatic involvement in abdominal TB: a clinical, biochemical and histopathological study. J Assoc Physicians India 1972;20(11):843-7.

19. Jones JM, Peck WM. Incidence of fatty liver in TB with special reference to tuberculous enteritis. Arch Int Medicine 1994;74:341-7.

20. Scheuer PJ, Ashrafzdeh P, Sherlock S, et al. The pathology of hepatitis C. Hepatology 1992;15(4):567-71.

21. Bach N, Thung SN, Schaffner F. The histological features of chronic hepatitis C and autoimmune hepatitis: a comparative analysis. Hepatology 1992;15(4):572-7.

22. Gerber MA, Krawczynski $K$, Alter MJ, et al. Histopathology of community acquired chronic hepatitis $\mathrm{C}$ the sentinel counties chronic non-A, non-B hepatitis study team. Mod Pathol 1992;5(5):483-6.

23. Roberts JM, Searle JW, Cooksley WG. Histological patterns of prolonged hepatitis $\mathrm{C}$ infection. Gastroenterol Jpn 1993;28(5):37-41.

24. Lefkowitch JH, Schiff ER, Davis GL, et al. Pathological diagnosis of chronic hepatitis $\mathrm{C}$ : a multicentre comparative study with chronic hepatitis B the hepatitis interventional therapy group. Gastroenterology 1993;104(2):595-603.

25. Czaja AJ, Carpenter HA. Sensitivity, specificity and predictability of biopsy interpretations in chronic hepatitis. Gastroenterology 1993;105(6):1824-32.

26. Kumar D, Farrell GC, Fung C, et al. Hepatitis C virus genotype 3 is cytopathic to hepatocytes: reversal of hepatic steatosis after sustained therapeutic response. Hepatology 2002;36(5):1266-72.

27. Rozario R, Ramkrishna B. Histopathological study of chronic hepatitis $\mathrm{B}$ and $\mathrm{C}$ : a comparison of two scoring system. J Hepatol 2003;38(2):223-9.

28. Amarapurkar AD, Sangle NA. Histological spectrum of liver in HIV-autopsy study. Ann Hepatol 2005;4(1): 47-51.

29. Sung KC, Ryan MC, Wilson AM, et al. The severity of nonalcoholic fatty liver disease is associated with increased cardiovascular risk in a large cohort of non-obese Asian subjects. Atherosclerosis 2009;203(2):581-6.

30. Grieco A, Forgione A, Miele L, et al. Fatty liver and drugs. Eur Rev Med Pharmacol Sci 2005;9(5):261-3.

31. Chalasani N, Wilson L, Kleiner DE, et al. Relationship of steatosis grade and zonal location to histological features of steatohepatitis in adult patients with non-alcoholic fatty liver disease. Journal of Hepatology 2008;48(5): 829-34. 
32. Gordon A, McLean CA, Pedersen JS, et al. Hepatic steatosis in chronic hepatitis B and C: predictors, distribution and effect on fibrosis. Journal of Hepatology 2005;43(1):38-44.
33. Amarapurkar A, Ghansar T. Fatty liver: experience from western India. Annals of hepatology 2007;6(1):37-40.

34. Amarapurkar A, Agrawal V. Liver involvement in TB-an autopsy study. Tropical Gastroenterology 2006;27: 69-74. 